\title{
Empirical Analysis on the Development Level of Sichuan High-tech Service Industry
}

\author{
Can Wang ${ }^{1, *}$ \\ ${ }^{1}$ School of Mathematics, Chengdu Normal University, Chengdu, Sichuan 611130, China \\ *Corresponding author.Email:061035@cdnu.edu.cn
}

\begin{abstract}
In order to do a good job of the comprehensive development of Sichuan's high-tech service industry, this paper first builds an evaluation index system from the four dimensions of basic resources, hightech input, market share and service output. Then the system clustering method is used to cluster the high-tech service industry in the province. The results are clustered into four categories and the clustering effect is obvious. At last, the spatial distribution of each category is analyzed, and the spatial relationship between each category and transportation distance and population density is discussed. At the same time, policy recommendations for further development are proposed.
\end{abstract}

\section{Keywords: Sichuan province, high-tech service industry, clustering, spatial distribution}

\section{INTRODUCTION}

The rapid development of the global economy has promoted the reform of the production industry. Among them, the high-quality service industry has taken an increasingly prominent dominant position in the economic market. Due to its high intensity radiation, high innovation value and high technology content, the mode of technology service industry has gradually changed. According to the results of the fourth economic census in China, the production efficiency of high-tech service industries will be steadily improved, and the situation of promoting information service operations through infrastructure upgrades is more concentrated, and the prominent agglomeration effect has also promoted the advantageous development of the regional economy.

As an engine to promote technological reform, hightech service industry is an indispensable part of modern service industry and a high-end link of the market economy, so its research materials are also quite rich. Among them, there are more representative examples in China. Scholar Wang Zhengxin's empirical research method based on factor analysis and improved cluster analysis, comprehensively evaluated the development level of high-tech service industry from the national region; scholar Liu Qing made a detailed analysis of the spatial pattern and influencing factors of Shenzhen high-tech enterprises based on spatial correlation measures; scholar Su Hua, using Suzhou as an example,

*Fund: Research project of Chengdu Normal University "Research on the Development Status and Spatial Structure of Hightech Service Industry in Sichuan Province" (CS19ZB08)

CLC number: C8; F8. Document code: A studied the construction of an evaluation index system for the development of high-tech service industries using AHP; scholar Wang Yangdong analyzed and researched the development countermeasures of China's high-tech service industry from a macro level, and so on. It is not difficult to find that the previous research of scholars is of great significance, and it is of great value to the evaluation, development, and countermeasures of high-tech service industries. As a representative province for the rapid development of the central and western regions of China, Sichuan province is also in urgent need of completing the development status and empirical analysis of the high-tech service industry in this province. This article will give a brief overview of the current status of the development of high-tech services in the province. After constructing the evaluation index system, the system will be specifically clustered with the system clustering method, and a category spatial distribution map will be made to explore the spatial relationship between clustering results and indicator patterns in detail.

\section{REGIONAL OVERVIEW AND INDICATOR SELECTION}

\section{A. Brief description of the region}

Sichuan province is located in the hinterland of southwest China and its capital is Chengdu. It has been known as the "Land of Abundance" since ancient times. It has an excellent geographical location. It is adjacent to Shaanxi, Gansu, Yungui, Chongqing and other provinces and cities. The province has a diverse terrain and vast area, ranking fifth in the country. There are 21 administrative areas in the area with a large population, diverse ethnic groups, and rich cultures, which provide 
the basis for the development of high-tech industries. As a gateway to western China, Sichuan province has been focusing on developing a high-tech economy in recent years. In particular, according to the national policy of the western region, it has made outstanding achievements in transportation and talent introduction, laying a foundation for the development of high-tech service industries.

\section{B. Establishment of indicator system}

The economic development foundations and levels of various cities in Sichuan province are quite different, and the advantages and disadvantages of the high-tech service industry are also different in different regions. Based on the national classification of high-tech service industries, and based on the principles of comprehensive system and available data, this article will construct an evaluation index system from the four dimensions of prerequisites, input funds, product share and service output. The detailed indicators are shown in "Table I".

TABLE I. EVALUATION INDEX SYSTEM OF SICHUAN HIGH-TECH SERVICE INDUSTRY DEVELOPMENT LEVEL

\begin{tabular}{|c|l|}
\hline Primary indicators & \multicolumn{1}{c|}{ Secondary indicators } \\
\hline \multirow{4}{*}{ Basic resources } & Education quantity (research institutions and number of higher education institutions) \\
\cline { 2 - 2 } & Traffic volume (subway, highway, railway mileage) \\
\cline { 2 - 2 } & Population density \\
\cline { 2 - 2 } High-tech investment & Consumption Structure Ratio \\
\cline { 2 - 2 } & Total investment \\
\cline { 2 - 2 } Market share & R \& D funding \\
\hline \multirow{3}{*}{ Service output } & Product share \\
\cline { 2 - 2 } & Number of services \\
\hline & Main income \\
\cline { 2 - 2 } & Number of intellectual property \\
\cline { 2 - 2 } & total assets \\
\hline
\end{tabular}

In the establishment of the evaluation index system, the basic resources mainly consider the basic conditions for the development of high-tech services. Excellent higher education and convenient shelter and travel can better attract high-tech talents. High-tech investment measures the development advantages and potential of the high-tech service industry from the financial perspective, especially the high investment in research and development and personnel can bring higher probability and high returns. The operation status of high-tech service companies is examined by taking market share as an indicator. Finally, its innovation output and sustainable development are evaluated based on service output. The index data comes from Sichuan Statistical Yearbook, Economic Census and High-tech Industry Survey.

\section{EMPIRICAL ANALYSIS}

\section{A. Cluster analysis}

The research data show that the agglomeration effect of the high-tech industry is obvious. In order to discuss the spatial agglomeration effect of the high-tech service industry in Sichuan, this paper chooses the classic system clustering method for analysis. According to the constructed index data matrix, first, the 21 cities in the province are classified into one category, and then new categories are merged according to the data distance of each type, and this step is repeated until all the cities are not in the same category.
The statistical analysis software SPSS is used to perform the clustering operation. The specific process is to import data, select analysis and classify to systematically cluster, and obtain an icicle clustering diagram. In order to make the results more scientific and reasonable, according to the economic development of each city, the high-tech service industry areas in Sichuan province were finally grouped into four categories. The results are shown in "Table II".

The clustering results show that the high-tech service industries in 21 cities in Sichuan province are clustered into four categories. The first category is Chengdu, the provincial capital, and Mianyang, a city with a "science and technology city". The 4 common cities in the fourth category have obvious common points. For example, they are all cities with a large number of ethnic minorities and relatively backward transportation. In order to facilitate the analysis of the results of the index, the spatial pattern display of the clustering results is continued. 
TABLE II. CLUSTERING RESULTS OF REGIONAL DEVELOPMENT LEVEL OF HIGH-TECH SERVICE INDUSTRY IN SICHUAN PROVINCE

\begin{tabular}{|l|l|l|l|l|l|l|l|l|}
\hline Category & Number of cities & \multicolumn{9}{|c|}{ Specific city name } \\
\hline I & 2 & & Chengdu & Mianyang & & & & \\
\hline II & 6 & & Meishan & Ya'an & Deyang & Ziyang & Panzhihua & Nanchong \\
\hline III & 9 & $\begin{array}{l}\text { Leshan } \\
\text { Zigong }\end{array}$ & $\begin{array}{l}\text { Yibin } \\
\text { Luzhou }\end{array}$ & $\begin{array}{l}\text { Neijiang } \\
\text { Suining }\end{array}$ & $\begin{array}{l}\text { Guang'an } \\
\text { Guangyuan }\end{array}$ & Dazhou & \\
\hline IV & 4 & Liangshan & Garze & Aba & Bahzong & & \\
\hline
\end{tabular}

\section{B. Spatial pattern analysis}

In order to further discuss the regional development of high-tech service industry in Sichuan province, the spatial pattern analysis is first performed based on the clustering results, as shown in "Fig. 1".

It can be seen from the distribution between spatial categories that the distribution of high-tech service industries in the province is graded, and the fourdimensional indicators corresponding to the evaluation are concentrated. Chengdu and Mianyang, as specific regions in the province, have their own category, and the sparseness of spatial distance in the fourth category is also a major feature of clustering. Due to the influence of the number and scale of high-tech service enterprises, the differences in the distribution of the spatial pattern are also obvious. The number and scale of high-tech enterprises in the first two cities have obvious advantages over other cities. The service industries that the four cities in the fourth category focus on are not high-tech, but their innovation investment is gradually expanding. According to the economic development and policy tilt, breakthroughs in high-tech innovation can be expected in the next few years. Different from the high concentration areas of the first type and the low concentration areas of the fourth type, the spatial effects of the high and low concentration areas of the second and third types are obvious, that is, the advantages and disadvantages of the second and third types are more prominent than surroundings. For example, in the second category, Meishan, Ya'an and other cities, from the perspective of basic resources, their own advantages are obvious. In the future, if they increase their input in the future, they are expected to increase their market share in service output.

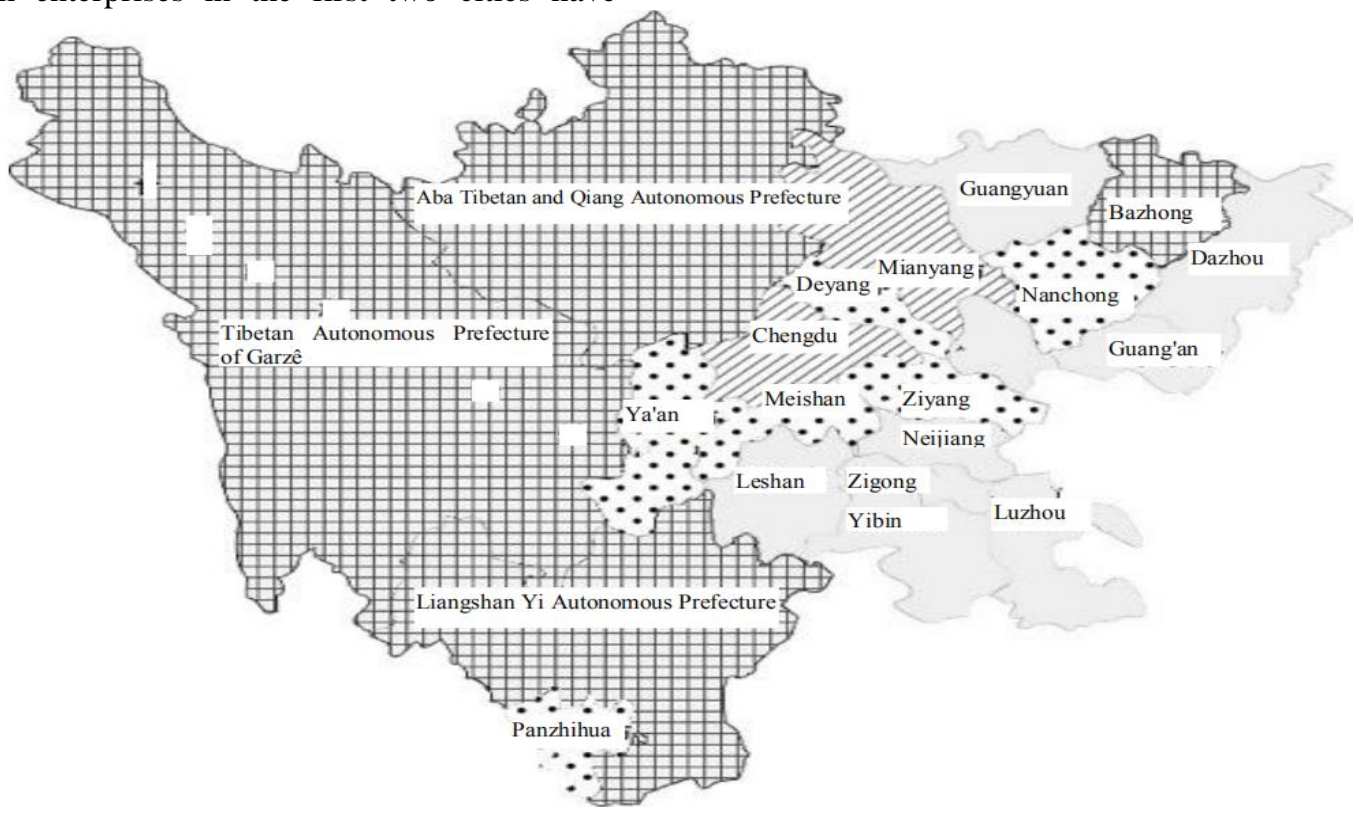

Fig. 1. Spatial distribution pattern of high-tech service industry in Sichuan province.

It can be seen from the distribution of spatial categories that the distribution of high-tech service industries in the province is closely related to the index of basic resources. First of all, from the perspective of the spatial relationship with transportation, the two cities in the first category have convenient transportation. Especially Chengdu is the capital of
Sichuan province. Its subway, railway, highway, airport and other transportation are the most convenient. Chengdu and Mianyang, which are closely connected to each other, are relatively close in space. The educational resources of both, especially the resources of higher education, are also the most abundant in the province. The second category of Panzhihua is far from 
the first category in terms of spatial distance, but the city relies on its unique geological conditions to establish many high-tech enterprises specializing in management services and development monitoring of rare ore resources, greatly weakening its unfavorable transportation and other basic resources. In terms of population density, the four cities in the fourth category are the smallest, and because these cities have a vast territory, and they are ethnic minority population centers, their population density cover the incompetence of information such as labor acquisition, housing prices, and demand, while high-tech service industries need modern innovative talents, and obviously the choice of talents will tend to other regions with more abundant basic resources. The spatial distribution of high-tech service industries is also inseparably linked to innovation industry resources, innovation and entrepreneurship parks, etc. The known spatial distribution and high-tech radiation are centered on industrial agglomeration and form a healthy competition. The intensive spatial agglomeration of high-tech enterprises will form an innovation environment of knowledge diffusion and mutual service.

\section{CONCLUSION}

This article first builds an evaluation index system for evaluating Sichuan's high-tech service industry in four dimensions: basic resources, high-tech input, market share and service output. Then it clusters hightech service industries in 21 cities in the province. The results show that there are four types of clustering. Finally, the spatial distribution of the categories is analyzed from the category and the category itself, and the spatial correlation with population density and traffic conditions is discussed in detail. In general, the agglomeration effect of high-tech services in Sichuan province is obvious. Chengdu and Mianyang are the leading cities for economic development in the province. They are self-aggregated into the first category, and high, cold and remote cities where ethnic minorities gather are in the fourth category. In addition, there are some special cases in the category, and factor analysis is also carried out in this thesis. In the discussion of spatial pattern distribution, basic resources are the most important primary indicators, because other indicators are greatly affected by it. The development indicators of high-tech service industries in the second and third categories need to be improved and innovated. For example, Meishan, Deyang and other cities in the second category can focus on the introduction of high-tech funds with convenient transportation.

In general, cities and provinces in Sichuan province need to increase the development of high-tech service industries on the basis of existing conditions, create new policy conditions to support technological innovation and output and establish industrial policies that promote the synchronous development and improvement of the entire region. In particular, for the four regions in the fourth category, high-level talents need to be introduced to increase scientific and technological innovation and technical services. The whole province should radiate with Chengdu as its core, promote technical service cooperation in four categories and cities, establish sharing mechanisms and platforms, and gradually realize the common development of hightech service industries across the province.

\section{References}

[1] Wang Yangdong, Yang Yuecheng, Zhao Zhiqiang. Connotation characteristics and cause analysis of high-tech service industry [J]. Science of Science and Technology Management (11): 1215. (in Chinese)

[2] Wang Yangdong, Zhang Jun, Feng Li. Research on Evaluation Methods of High-tech Service Industry Projects [J]. Science \& Technology Progress and Countermeasures (8): 121-123. (in Chinese)

[3] Yao Zhenghai, Yao Peiyi, Wang Shanshan. Study on the Evaluation of the Development Level of Regional High-tech Service Industry in China - Based on the Principal Component Analysis [J]. Economic Issues, 2014 (11): 70-74. (in Chinese)

[4] Chen Bowen. The development of high-tech service industry in China's underdeveloped cities - Taking Chongqing as an example [J]. Journal of Shanxi University of Finance and Economics, 2010 (s2): 142-142. (in Chinese)

[5] Zha Yingdong, Mei Qiang, Li Wenyuan. Research on the Cultivation and Development of High-tech Service Industry in Jiangsu Province [J]. Jiangsu Social Sciences (2): 269-273. (in Chinese)

[6] Jensen J B . Trade in High-Tech Services [J]. Journal of Industry, Competition and Trade, 2008, 8(3-4):181-197.

[7] Li-Wei C , Wei S , Jiu-Yun W . Innovation Efficiency and Determinants in Chinese High-Tech Industry [C] // International Conference on Management \& Service Science. IEEE, 2009.

[8] Shao Changan, Guan Xin, Ye Zhonghua. Research on the Relationship between Beijing's High-tech Industry and Regional Economic Development [J]. Management Review, 2019 (9). (in Chinese) 